\title{
A Comparative Study of Language Attitudes in Hong Kong: Towards English, Cantonese and Putonghua
}

\author{
Xiaokai Liu ${ }^{1}$ \\ ${ }^{1}$ College of Liberal Arts and Social Sciences, City University of Hong Kong, Hong Kong, China \\ ${ }^{2}$ Chi Feng No. 2 Senior High School, Chi Feng, China \\ Correspondence: Xiaokai Liu, English Division, Chi Feng No.2 Senior High School, Chi Feng 024000, Inner \\ Mongolia Autonomous Region, China. E-mail: Kerry20086@163.com
}

Received: January 15, 2018 Accepted: January 30, 2018 Online Published: February 10, 2018

doi:10.5539/ijel.v8n3p195

URL: http://doi.org/10.5539/ijel.v8n3p195

\begin{abstract}
20 years have elapsed since Hong Kong has returned to China and the connections with Mainland China are growing in different domains. Especially, the universities in Hong Kong attracted a large number of Mainland students and the number is increasing. Therefore, it is interesting to examine the language attitudes towards English (the former British colonial language), Cantonese (the local dialect) and Putonghua (the third official language) from the perspective of local students and Mainland students. The study reported in this thesis is a quantitative investigation of 30 local students and 30 Mainland students from different disciplines at City University of Hong Kong. Their attitudes towards three languages were compared in terms of integrative orientation and instrumental orientation. The results revealed the local students hold a more integrative attitude and showed their strong loyalty to Cantonese while Mainland students showed integrative attitude and favored the use of more Putonghua in different language contexts. English was still regarded as a prestigious language from both the integrative and instrumental perspective by the local students and the Mainland students. Besides, interactional language preference between the Mainland students and the Local students was also investigated and the result showed English was the most preferable language. The findings of this study suggest Cantonese remains as a strong dialect; English still will be the linguistic capital and the pragmatic function Putonghua is developing well in Hong Kong. Results also indicate subtle transition towards Trilingualism among the university students in Hong Kong.
\end{abstract}

Keywords: language attitudes, Hong Kong, Mainland student, local students

\section{Introduction}

Known as "The Pearl of the Orient", Hong Kong is a dynamic city also with a dynamic linguistic situation. The linguistic situation of Hong Kong actively interacts with the changes of time and the sociopolitical environment which has always caught the attention of researchers and educators. It is the fluid nature of this topic that made the linguistic situation in Hong Kong fresh and complex (Lai, 2005).

The Language situation in Hong Kong is accompanied by its history. Hong Kong had become a British colony since 1841 and after 155 years of British colonial rule, Hong Kong ceased from British sovereign and became a special administrative region (SAR) of People's Republic of China (PRC) in 1997. During this period, Hong Kong twice experienced a language shift — the first shift to English, the colonial language and the second shift to Putonghua, the third official language. These two languages along with the local dialect, Cantonese, made the language situation in Hong Kong rather complicated and gave room for a large number of studies to explore in this field (e.g., Gu, 2011; Hyland, 1997; Lai, 2001, 2005; etc.).

Before handover, English functions in different domains as the official language in Hong Kong and is accompanied by Cantonese which is used as a dialect for daily communication by local residents. These two languages formed a diglossic situation rather than a bilingual situation' in Hong Kong (Fishman, 1967), which means English and Cantonese are used within the same community by two monolingual groups in which English is used for "high" variety of social purpose, for example writing, and Cantonese is used for "low" variety such as daily conversation. Actually, the case of diglossia in Hong Kong is rather interesting as Fasold (1984) describes as "double overlapping diglossia" in which English plays the " $\mathrm{H}$ " role corresponding to Chinese; within the 
Chinese language itself, Standard Chinese also plays an "H" role in relationship to the "L" role of Cantonese. In fact the number of bilingual people grows, as Lords suggested (1987), when Hong Kong quickly developed into an international finical center in the 1980s as well as the compulsory education with English as the medium of instruction language for most schools.

After the handover, Putonghua was officially brought in Hong Kong. Hong Kong has moved into a new linguistic situation where three languages function in different domains. The postcolonial situation in Hong Kong gives more room for Putonghua to burgeon. For example, changes took place in education that Putonghua has become the core subject in the school curriculum from Primary 1 to Secondary 3 in 1998. Besides, Putonghua has also become an elective subject for the Hong Kong Certificate of Education Examination in 2000.

In addition, as a gesture of decolonization, the new HKSAR government also announced the mandatory Mother Tongue Education Policy two months after the handover in 1997. As a result, more than 70 percent of the secondary schools adopted Chinese (standard written Chinese and spoken Cantonese) as the medium of instruction whereas up to 90 percent of secondary schools in Hong Kong used English as the medium of instruction before 1997.

Twenty years elapsed since Hong Kong has returned to China and it is interesting to discover what the language attitudes are now. Among different kinds groups of people in Hong Kong, there is a notable group of people who has experienced the change of the sovereignty, Mother Tongue Education Policy. These people also exposed to Putonghua as a core subject when they are just starting their primary education. These students compared with previous secondary students respondents (Lai, 2005, 2011), are companied by these three languages in their primary education rather than in their secondary education. This generation of students under the current survey is now in their tertiary study and has been brought up under new policies and new political system since their primary education. Besides, university students are expected to present a more definite response to some relatively complex issues of languages, politics and ethnicity than school children (Hyland, 1997).

This study aims to investigate the language attitudes towards three official languages (namely, Cantonese, English and Putonghua) both from the local university students' perspective and the Mainland students' perspective. The results of their attitudes will be analyzed and compared.

\section{Previous Studies of Language Attitudes in Hong Kong}

Early works on the definition of attitudes dated back to Thurstone (1931), who defined attitudes as "affect for or against a psychological object" which contains both the positive and negative emotional responses that attitudes embody (Peter, 2010). An often cited definition of attitudes was "a learned disposition to think, feel and behave toward a person or object in a particular way (Allport, 1954)" Attitudes are latent and the processing systems are internal and hidden therefore, attitudes cannot be directly measured (Baker, 1992).

One of the influential studies in Hong Kong which has enlightened and also attracted many replication studies was conducted by Pierson, Fu and Lee in 1980. In their study, Pierson et al. surveyed 466 Hong Kong secondary (Form 4) students' attitudes towards English and Chinese by using the direct and indirect method. For example, asking students to rate their ideal selves and what they would like to be a native Chinese people in Hong Kong, or a native English speaker in Hong Kong. Although the results of the indirect method did produce some insights however, it was not as strong as the direct method. Results through the direct method showed that students had positive attitudes towards English and agreed with the practical function of English in Hong Kong. In addition, students also showed a kind of patriotic feelings when using English because that would threaten their Chinese identity.

Two replication studies have later been conducted. One was done by Pennington \& Yue (1994) who performed a survey which involved 285 Hong Kong secondary students studying at public schools from upper classes (Band 1) to lower classes (Band 5). The students were asked to do a questionnaire which was the same as the one used by Pierson et al. The results of their survey also showed that the participants had a positive attitude toward English. However, the students in Pennington \& Yue's study did not feel unpatriotic when speaking English. Thus Pennington and Yue stated the old belief in 1980s had been out of the date.

The second replication study was conducted by Axler, Yang, \& Stevens (1998) and their results supported Pennington \& Yue's study. As Axler et al. concluded English was no longer the colonizer's language, but was seen as an international language which functions much in Hong Kong. This showed the definite changes among the students.

Pierson (1994) conducted a study using an exam question to explore 100 post-secondary students' attitudes toward Putonghua. 350 words were required for the question of whether Putonghua should be made a 
compulsory subject. Contents analysis was used in this study and the results showed that many students had a positive attitude towards Putonghua. However, Yau (1992) once criticized the reliability of applying an indirect method of measuring language attitude. In addition the data was collected during the exam, which would guarantee the result because students' answers may aim for passing the exam instead of writing their own opinions.

Using another questionnaire, Hyland (1997) carried another survey by categorizing the items in the questionnaire under five factors. The respondents of this research were 900 undergraduate students. A 4-point Likert scale was applied and the results showed English was still recognized for its instrumental value, however, it was not a significant language as Cantonese. Although English, Cantonese, and Putonghua were all mentioned in the in Hyland's study, all of the five factors were designed with English as the focus (Lai, 2005). The research on language situation in Hong Kong still favors English.

Lai (2001) conducted a survey to find out the attitudes of Hong Kong secondary school students towards three languages (English, Cantonese and Putonghua) by using questionnaires also on a 4-point Likert scale given to 134 students. This study was done by comparing language attitudes towards these languages between the two social groups: the middle-class (elite students) and the working-class (low achievers). Results showed both groups of students showed a positive attitude towards Putonghua as well the other two languages. English was favored by the middle-class while Cantonese was used most among the working class.

However, as the working-class students in Hong Kong tend to receive education in Chinese or attend schools in which Cantonese is used as the medium of instruction. Meanwhile the middle-class students are more likely to have an English education background. The results may have much to do with their education background rather than their social class background.

Lai (2005) carried out another survey. This time the social class was ignored. A quantitative investigation (questionnaires) of 1048 Hong Kong secondary school students was carried in order to find out the language attitudes toward three languages in Hong Kong. The results of this research showed that Cantonese was still favored by most of the students for daily communication purpose. English as a language has more practical value and social status, while Putonghua still ranked a relative lower position and still need time to be accommodated.

In the study, Lai applied the notion of integrative and instrumental orientation which was proposed by Gardner \& Lambert (1972) to categorize students' attitudes towards these three languages. The notion of "integrativeness" refers to a desire to learn a language in order to "come closer to the other language community (Gardner, 2001)" and Gardner's (1985) socio-educational model of SLA, learners who showed the characteristic of "integrativeness" were said to have an integrative orientation towards the language and had a favorable attitudes towards the language community (Lamb, 2004). The instrumental orientation refers to the instrumental value of the language. A positive inclination may show to a language for its practical purposes, for example obtaining a job (Lai, 2005).

Based on this framework, all the items in questionnaire were designed and categorized under six parameters in Lai's study (2005): the integrative orientation towards English, the integrative orientation towards Cantonese, the integrative orientation towards Putonghua; the instrumental orientation towards English, the instrumental orientation towards Cantonese and the instrumental orientation towards Putonghua. In this way, students' attitudes towards each language can be examined from two aspects, namely, integrativeness and instrumentalism.

From the previous literature, most studies chose the Hong Kong secondary students as their respondents however, in this study university students in Hong Kong were chosen as the respondents. In addition, this study is also going to involve the Mainland students studying in universities of Hong Kong as the respondents too. Their attitude towards these three languages will be analyzed and compared with the local students.

\section{Research Method}

Under the theoretical background and previous studies, this study continues to investigate language attitudes in Hong Kong by using a direct method - questionnaires and Likert scale. Based on the above introduction and the understanding of integrative and instrumental orientation, this study addresses the following research questions:

1). What is the local university students' language attitude towards English, Cantonese and Putonghua in terms of integrative orientation and instrumental orientation?

2). What is the Mainland university students` language attitude towards English, Cantonese and Putonghua in terms of integrative orientation and instrumental orientation during their study in Hong Kong?

3). What are the similarities and differences between the Local students and the Mainland students in terms of 
preference to these three languages being used in Hong Kong?

\subsection{Research Tool}

This research adopted a quantitative method through a questionnaire survey conducted a group of local and a group of Mainland students. The questionnaire (see Appendix) was adapted from Lai (2005) with necessary modification in order to elicit some differences in language attitudes. The questionnaire consists of two parts. The first part was designed to solicit information about the language background of both Mainland and local respondents. This section also carries an additional question which aims to survey the attitude of the students with different cultural background toward the Hong Kong people's identity. The second part of the questionnaire was composed of 20 statements which are all about participants' language attitude towards English, Cantonese and Putonghua.

Following the practice in the previous studies surveyed in the Literature Review, a five-point Likert scale with "1" meaning strongly disagree" and " 5 " meaning strongly agree" was used. Respondents to the questionnaire were asked to rate each of the 20 statements using the Likert-scale.

\subsection{Data Collection Procedures}

A total of 67 students majoring in different subjects in the City University of Hong Kong (City U) were invited to complete the questionnaire through convenience sampling and judgment sampling. The survey was administered in two different periods. It was first conducted in some of the EAP Classes (see the note) of the City University of Hong Kong through convenience sampling. Students in different majors of 3 classes voluntarily participated in this survey. Among the respondents, 36 are local students and 10 students are Mainland students. The questionnaires were administered when students attended the EAP class. To ensure reliability of the data, all the questionnaires were administrated by the researcher himself with the same instructions and 15-20 minutes were given to students to complete the questionnaire.

Due to the unequal number of local respondents and Mainland respondents in the EAP classes, the research conducted the second survey through judgment sampling which looked for respondents meeting specific requirements (Mainland students studying at the universities of Hong Kong) of the study. As a result, more Mainland respondents were involved in this study. All the Mainland participants in this survey were clearly informed the purposes of the questionnaire and they all participated in the survey voluntarily. In the end, 21 Mainland students agreed to do the questionnaire. These students did the questionnaire under the supervision of the researcher with the same instruction and time duration. As a result, 36 local students and 31 Mainland students in total were involved in this survey.

\subsection{Data Analysis}

A total of 67 questionnaires were administered and all were returned. To ensure the reliability of the result, initial checking of the responses to each questionnaire was carried out. Eventually, 5 questionnaires were excluded due to the ambiguous answers (e.g., same rating given to all items that need to be responded to on the Likert scale and two or more ratings were circled for some of the items and skipping some of the questions) and the unintelligibility of the written answers to questions that ask for personal details or some elaboration. Therefore, only 62 questionnaires were qualified for the analysis, which included 32 from the local students and 30 from the Mainland students. Since this is a comparative study, the equal sampling in each group would be ideal, 2 questionnaires from the local group were randomly excluded. In the end, there were a total of 60 questionnaires (30 questionnaires of local students and 30 questionnaires of Mainland students) which was used for the coming analysis.

Descriptive statistical analyses were performed on the responses to each of the items on the questionnaire. The percentage was calculated for the first part of the questionnaire. For the second part of the questionnaire, Means and standard deviations (SD) were calculated with each statement. Means value of any statement which was smaller than 3 showed an inclination towards disagreeing with that statement, while Means value greater than 3 revealed an inclination towards agreeing and SD values showed the different disparity among respondents.

\subsection{Profile of the Respondents}

All of the respondents were ethnic Chinese (aged 19-23) born in Hong Kong or Mainland China and were all under different Bachelor Degree or Associate programs in Hong Kong currently. Since language majors may have bias to a particular language, none of the respondents in this study was language majors (see Table 1). 
Table 1. Disciplines of the respondents

\begin{tabular}{llll}
\hline Discipline & & Local students & Mainland students \\
\hline Science & Bachelor of Science in Architectural Studies & 6 & 2 \\
Stream & Associate of Science in Building Services Engineering & 4 & 3 \\
& Bachelor of Science in Creative Media & 5 & 0 \\
& Bachelor of Science in Architectural Studies & 0 & 5 \\
& Bachelor of Science in Computing Mathematics & 0 & 7 \\
\hline Arts & Bachelor of Social Science in Social Work & 5 & 2 \\
Stream & Bachelor of Social Science in Psychology & 2 & 2 \\
& Bachelor of Arts in Media and Communication & 5 & 9 \\
& Bachelor of Arts in Creative Media & 3 & 0 \\
\hline Total & & 30 & 30 \\
\hline
\end{tabular}

As shown in Table 1, 30 of the respondents were local respondents and 30 respondents were from Mainland China and were non-Cantonese native speakers. Most of them have been in Hong Kong for two years and they were born in different provinces of China. As Table 2 shows the information of the 30 Mainland students whose questionnaires were analyzed in this research.

Table 2. Information of the Mainland respondents

\begin{tabular}{|c|c|c|c|c|c|c|c|}
\hline \multicolumn{3}{|c|}{ Length of stay Hong Kong } & \multicolumn{3}{|c|}{ Birthplace } & \multirow{3}{*}{ Beijing } & \multirow{3}{*}{$\begin{array}{l}\text { Hunan } \\
\text { Province }\end{array}$} \\
\hline Less than & 2 years & more than 2 years & Northeast of & Zhejiang & Shaanxi & & \\
\hline 2 years & & & China & Province & Province & & \\
\hline 5 & 14 & 11 & 9 & 6 & 6 & 5 & 4 \\
\hline Total & 30 & & 30 & & & & \\
\hline
\end{tabular}

\section{Result Analysis and Discussion}

\subsection{Language Background of the Respondents}

Table 3 presents the percentages of the 30 local and 30 Mainland respondents' feedback to the relevant questions. As shown in the table, all the local students $(\mathrm{N}=30)$ spoke Cantonese and it was also the most commonly used language with $96.7 \%$ of the students $(\mathrm{N}=29)$ used it in their daily life. $73 \%$ of the local students $(\mathrm{N}=22)$ could speak Putonghua, but only 3.3\% ( $\mathrm{N}=1)$ of the students used it in daily life. As for English, the situation was similar to Putonghua, with $60 \%$ of the local students $(\mathrm{N}=18)$ could speak it and only $10 \%$ of students $(\mathrm{N}=10)$ used it a lot in their life. At the same time, $6.7 \%$ of the local students $(\mathrm{N}=2)$ spoke Teochew hua and Hakka which were used often in these two students' daily life.

Regarding Mainland respondents, all the respondents ( $N=30)$ from Mainland China spoke Putonghua with 66.7\% of the students $(\mathrm{N}=20)$ used it often in Hong Kong. Nearly half of the Mainland students $(\mathrm{N}=14)$ also spoke their local dialect such as, Shaanxi dialect, Shanghai dialect, Xiang Chinese(a dialect spoken mainly in Hunan province), Northeastern Mandarin(a dialect spoken in Northeastern part of China), and Beijing dialect in addition to Putonghua, but only 3 students reported that they still used their dialects in Hong Kong. As regarding Cantonese (the local dialect of Hong Kong), 7 students reported that they acquired it in Hong Kong and 5 of them used it quite often. Concerning English, more than half of the Mainland students $(\mathrm{N}=16)$ could speak English and among them 4 students reported that they used it very often in their daily life in Hong Kong.

Table 3. Language background of the respondents

\begin{tabular}{|c|c|c|c|c|c|c|}
\hline \multirow{2}{*}{\multicolumn{2}{|c|}{ Questions }} & \multirow[t]{2}{*}{ Options } & \multicolumn{2}{|c|}{ Local students } & \multicolumn{2}{|c|}{ Mainland students } \\
\hline & & & $\%$ & No. of students & $\%$ & No. of students \\
\hline \multirow[t]{4}{*}{3.} & What language(s) /dialect(s) can you speak? & English & 60 & 18 & 53.3 & 16 \\
\hline & & Cantonese & 100 & 30 & 23.3 & 7 \\
\hline & & Putonghua & 73 & 22 & 100 & 30 \\
\hline & & Others & 6.7 & 2 & 46.7 & 14 \\
\hline \multirow{4}{*}{\multicolumn{2}{|c|}{$\begin{array}{l}\text { 4. What language (s) do you use most often in } \\
\text { your daily life in HK? }\end{array}$}} & English & 10 & 3 & 13.3 & 4 \\
\hline & & Cantonese & 96.7 & 29 & 16.7 & 5 \\
\hline & & Putonghua & 3.3 & 1 & 66.7 & 20 \\
\hline & & Others & 6.7 & 2 & 10 & 3 \\
\hline
\end{tabular}




\subsection{Integrative Orientation towards English, Cantonese, and Putonghua}

Statistics of statements relating to integrative orientation towards English (part of Research Question 1) are shown in Table 4. From the table, it can be observed that the local students show general positive attitudes towards English, as the mean values greater than 3 for each statement from the integrative perspective. The standard deviation (SD) values under this factor varies from 1.11 to 1.37, concerning SD value of Statement1, 15 and 20 which is relatively higher than Statement 3 and 18 respectively. The higher SD value reveals students' responses are not as consistent as the lower SD value for each statement. Therefore, it is unrealistic to conclude that all local students like to speak English and a Chinese person who speaks English in Hong Kong is considered highly educated (see Statement 1, 20). Although the mean value is 3.17 for the statement 15 (I like to speak English because it makes me feel westernized) which suggests local students show a positive inclination for this statement. The relatively high SD value (1.37) for this statement also indicates the divided opinions among the students. On the other hand, it seems the students like English speakers a lot in Hong Kong and they also tend to agree Hong Kong people should be fluent in speaking English as the highest mean values (3.50 and 3.60) shown in Statement 3 and 5. In addition, the comparatively lower SD values of these two statements also indicate the responses among students are almost unanimous.

The results of statements relating to integrative orientation towards English (part of Research Question 2) are illustrated in Table 4. The Mainland students show a positive inclination towards English, which is reflected by the mean values are all greater than 3 . While the SD values vary from 1.13 to 1.49 also suggest us the disparity in students' responses. In general, Mainland students favor English speakers in Hong Kong (see Statement 3) a lot, as the mean value for this statement is the highest (3.47), however, the SD values 1.38 indicates that the responses seem to be inconsistent. The same is the case with Statement 1 and 15, though viewed from the mean values a general positive attitude towards English could be drawn the relatively higher SD values tend to show students lack agreement.

From Table 4, some similarities and differences between the two groups of students in terms of preference to English (part of Research Question 3) can also be observed. Both groups of students like English and they hold positive integrative attitudes towards English. A possible explanation of this is that English is the medium of instruction in universities in Hong Kong.

Table 4. Integrative orientation towards English

\begin{tabular}{|c|c|c|c|c|c|}
\hline \multicolumn{2}{|c|}{ No. Statement } & \multicolumn{2}{|c|}{ Local } & \multicolumn{2}{|c|}{ Mainland } \\
\hline & & \multirow{2}{*}{$\frac{\text { Mean }}{3.40}$} & \multirow{2}{*}{$\begin{array}{l}\text { SD } \\
1.31\end{array}$} & \multirow{2}{*}{$\frac{\text { Mean }}{3.17}$} & \multirow{2}{*}{$\frac{\mathrm{SD}}{1.49}$} \\
\hline 1. & In Hong Kong I like to speak English. & & & & \\
\hline 3. & In Hong Kong I like the people who speak English. & 3.50 & 1.18 & 3.47 & 1.38 \\
\hline 5. & Hong Kong people should be able to speak fluent English. & 3.60 & 1.11 & 3.43 & 1.13 \\
\hline 15. & I like to speak English because it makes me feel westernized. & 3.17 & 1.37 & 3.03 & 1.40 \\
\hline 20. & A Chinese person who speaks English in Hong Kong is usually considered to be highly educated. & 3.53 & 1.35 & 3.33 & 1.27 \\
\hline
\end{tabular}

Table 5. Integrative orientation towards Cantonese

\begin{tabular}{|c|c|c|c|c|}
\hline \multirow[t]{2}{*}{ No. Statement } & \multicolumn{2}{|c|}{ Local } & \multicolumn{2}{|c|}{ Mainland } \\
\hline & Mean & SD & Mean & $\mathrm{SD}$ \\
\hline In Hong Kong I like to speak Cantonese. & 4.33 & 1.14 & 3.07 & 1.41 \\
\hline In Hong Kong I like the people who speak Cantonese. & 3.97 & 1.15 & 3.23 & 1.54 \\
\hline 5. Hong Kong people should be able to speak fluent Cantonese. & 4.13 & 1.28 & 4.23 & 1.15 \\
\hline (For Local students) I like to speak Cantonese because it is my mother tongue. & 3.53 & 1.31 & NA & NA \\
\hline Cantonese should be replaced by Putonghua since it is only a dialect. & 1.73 & 0.96 & 2.23 & 1.36 \\
\hline
\end{tabular}

As shown in Table 5, viewed from local students' responses, the means for statements relating to integrative orientation towards Cantonese (part of Research Question 1) are clearly greater than 3 except the last statement. This indicates a strongly positive inclination towards Cantonese is shown by the local students. In addition, the students show their disagreement on the replacement of Cantonese by Putonghua (see Statement 16) with the mean values 1.73. The SD values 0.96 for this statement also reveals the local students' answers are almost in consistency. On the whole, students seem to show their strong favor of Cantonese (see Statement 1. mean values 4.33 ranks the highest) and Cantonese speakers (see Statement 3. mean values 3.97). Students tend to agree that Hong Kong people should be able to speak fluent Cantonese. However, the SD values of this statement also indicate the inconsistency within the students' perceptions. This could be due to the fact that the New Immigrants 
in Hong Kong (migrants from Mainland China) and other immigrants are non-Cantonese native speakers.

Mainland students' integrative orientation towards Cantonese (part of Research Question 2) can be observed in Table 5. It seems the local dialect is favored by the Mainland students as the mean values clearly greater than 3 for the positive worded statement. Similarities and differences in statistics between two groups are shown in Table 5 (part of Research Question 3). Clearly, although Mainland students tend to show positive attitudes toward Cantonese, their responses are not as strong as the local students except Statement 5 as the mean values 4.23 which indicates the relatively high expectation of the Cantonese proficiency of Hong Kong people.

Table 6. Integrative orientation towards Putonghua

\begin{tabular}{|c|c|c|c|c|}
\hline Statement & \multicolumn{2}{|c|}{ Local } & \multicolumn{2}{|c|}{ Mainland } \\
\hline & Mean & SD & Mean & SD \\
\hline In Hong Kong I like to speak Putonghua. & 2.73 & 1.38 & 3.23 & 1.27 \\
\hline In Hong Kong I like the people who speak Putonghua. & 3.09 & 1.28 & 3.37 & 1.25 \\
\hline 5. Hong Kong people should be able to speak fluent Putonghua. & 3.03 & 1.38 & 3.47 & 1.36 \\
\hline $\begin{array}{l}\text { 13. (For Mainland China students) I like to speak Putonghua because it is my } \\
\text { mother tongue. }\end{array}$ & NA & NA & 4.03 & 1.07 \\
\hline $\begin{array}{l}\text { 17. I am afraid of speaking Putonghua in Hong Kong because others will think I } \\
\text { am a new immigrant from the Mainland. }\end{array}$ & 2.43 & 1.41 & 2.67 & 1.28 \\
\hline
\end{tabular}

Table 6 shows the statistics of statements relating to integrative orientation towards Putonghua (part of Research Question 1) in the perspective of the local students. The mean values for the statements lie predominantly around the region of 3 (neutral), which indicates that local students seem to have a neutral if not a slight inclination toward Putonghua. Although Local students feel positive about Putonghua speakers as they like the people who speak Putonghua in Hong Kong (see Statement 3) which the mean value is 3.09 and moreover, they have the tendency to disagree speaking Putonghua in Hong Kong would let others think I am a new immigrant from the Mainland (see Statement 17), the relatively greater SD values shown in the table reveal about the responses are not unanimous. Referring Table 3 Language background of the respondents only 1 out of 30 local students used Putonghua often in daily life, and then it is not surprising to find local students treat Putonghua as a school subject without strong affection.

From the Mainland students' responses, a clear positive attitude towards Putonghua can be observed as indicated by the statistics shown in Table 6 . Regarding the SD values in the table, it is obvious to find the SD values are relatively higher except for statement 17 (I like to speak Putonghua because it is my mother tongue). This may be due to some statements were worded in Hong Kong context while some are not.

As shown in Table 6 the similarities and differences between the two groups of students are clear in terms of their preference for Putonghua (Mainland students tend to have more positive attitudes to Putonghua compared with the local students but the degree of this integrative orientation towards Putonghua seem to be weakened in the context of Hong Kong (part of Research Question 3).

\subsection{Instrumental Orientation towards English, Cantonese, and Putonghua}

As shown from the statistical results in Table 7, Table 8, Table 9, respondents' instrumental attitudes towards English, Cantonese, and Putonghua (part of Research Question 1 and 2) as well as the similarities and differences in terms of preference to these three languages are examined below.

Table 7. Instrumental orientation towards English

\begin{tabular}{lllll}
\hline No. & \multicolumn{1}{c}{ Statement } & $\begin{array}{c}\text { Local } \\
\text { Mean }\end{array}$ & $\begin{array}{c}\text { Mainland } \\
\text { Sean }\end{array}$ & SD \\
\hline 2. & In Hong Kong I want to master a high level of English badly. & 3.67 & 1.32 & 3.77 \\
4. & Currently English is highly regarded in Hong Kong society. & 3.80 & 1.26 & 3.77 \\
6. & English is going to be important in the following years in Hong Kong. & 3.67 & 1.37 & 3.87 \\
7. & English will help me much to get a better job. & 4.03 & 1.19 & 4.23 \\
8. & English is now widely used in Hong Kong. & 3.47 & 1.20 & 3.63 \\
19. & English will let me have a chance to know more people. & 3.33 & 1.58 & 3.17 \\
\hline
\end{tabular}

As shown in Table 7, the high mean values for each statement tend to indicate local students' attitude towards English is clearly positive in the perspective of instrumental value. Among all of these statements, students tend 
to agree strongly that English may help them to obtain better jobs (see Statement 7). Moreover, local students agree English is highly regarded in Hong Kong society and it is one of the widely used languages in Hong Kong as the mean values shown in the table. Local students' learning motivation for English is positive as they tend to agree English is going to be important in the following years in Hong Kong. With British's leaving, English is predicted to fade its status and function. However, from the current results, it runs counter to the previous prediction; the status of English is unchanged.

Comparing the statistical results of all students' responses, we find both groups of the students hold high evaluation of English for its instrumental value and their degree is nearly the same except for some SD values which reveals a little disagreement among the perceptions. From the results it is obvious to notice that Mainland students tend to show a stronger tendency to master English well and they also rank highly the function of English as job seeking (part of Research Question 3).

Table 8. Instrumental orientation towards Cantonese

\begin{tabular}{|c|c|c|c|c|c|}
\hline \multirow[t]{2}{*}{ No. } & \multirow[t]{2}{*}{ Statement } & \multicolumn{2}{|c|}{ Local } & \multicolumn{2}{|c|}{ Mainland } \\
\hline & & Mean & $\mathrm{SD}$ & Mean & $\mathrm{SD}$ \\
\hline 2. & In Hong Kong I want to master a high level of Cantonese badly & 3.47 & 1.52 & 3.50 & 1.34 \\
\hline 4. & Currently Cantonese is highly regarded in Hong Kong society. & 3.37 & 1.60 & 3.47 & 1.36 \\
\hline 6. & Cantonese is going to be important in the following years in Hong Kong. & 3.13 & 1.26 & 3.03 & 1.58 \\
\hline 7. & Cantonese will help me much to get a better job. & 3.43 & 1.52 & 3.63 & 1.33 \\
\hline 8. & Cantonese is now widely used in Hong Kong. & 3.67 & 1.35 & 3.59 & 1.52 \\
\hline 14. & (For Mainland China students) I look for opportunities to practice Cantonese. & NA & NA & 3.37 & 1.65 \\
\hline
\end{tabular}

Statistics of statements relating to instrumental orientation towards Cantonese is shown in Table 8. From the table, it could be concluded that local students' attitude towards Cantonese is clearly positive with the mean values greater than 3 in each statement. It is surprising to find that local students would hold instrumental value towards Cantonese; especially this is the dialect that they have been using throughout their life. This reveals Cantonese as a local dialect still enjoys its instrumental value among the local students. However, the relatively grater SD values for some statement in this factor group tend to suggest the students' perceptions are not in consistency.

As the means values shown in Table 8, though the Mainland respondents are non-native Cantonese speakers, they tend to show a positive inclination to Cantonese in respect of instrumental value. On the whole, Mainland students want to master Cantonese and they agree that it is highly regarded and used in Hong Kong. They also agree strongly that Cantonese is the language for them to obtain jobs. For Statement 14, as the mean values is 3.37 which appears to be a probability that Mainland students would seek chances to practice this local dialect. However, the SD values, on the other hand, also have indicated the disparity in the perceptions, thus it is unrealistic to conclude that all Mainland students hold a high evaluation of Cantonese for its instrumental and social value.

Generally it seems both groups of students hold positive attitude to the instrumental value of Cantonese as the means value between the two groups is nearly the same except Statement 7 shown in the table. Mainland students seem to have a strong opinion that Cantonese will help me much to get a better job compared with the local students. The differences between the two groups are the SD values which indicate that though the overall attitudes towards Cantonese is the same, we can still notice that the perceptions in this regard is almost inconsistent (part of Research Question 3).

Table 9. Instrumental orientation towards Putonghua

\begin{tabular}{|c|c|c|c|c|c|}
\hline \multirow[t]{2}{*}{ No. } & \multirow[t]{2}{*}{ Statement } & \multicolumn{2}{|c|}{ Local } & \multicolumn{2}{|c|}{ Mainland } \\
\hline & & Mean & SD & Mean & SD \\
\hline 2. & In Hong Kong I want to master a high level of Putonghua badly. & 3.06 & 1.09 & 2.73 & 1.65 \\
\hline 4. & Currently Putonghua is highly regarded in Hong Kong society. & 2.77 & 1.49 & 2.83 & 1.38 \\
\hline 6. & Putonghua is going to be important in the following years in Hong Kong. & 3.03 & 1.47 & 3.43 & 1.56 \\
\hline 7. & Putonghua will help me much to get a better job. & 3.47 & 1.59 & 3.33 & 1.45 \\
\hline 8. & Putonghua is now widely used in Hong Kong. & 3.07 & 1.31 & 3.33 & 1.64 \\
\hline 12. & (For Local students) I look for opportunities to practice Putonghua. & 3.07 & 1.52 & NA & NA \\
\hline & $\begin{array}{l}\text { Putonghua will be used as a lingua franca (common language of } \\
\text { nunication or "link language") for Mainlanders, Taiwanese, and Hong Kong } \\
\text { e in the future. }\end{array}$ & 3.07 & 1.18 & 3.57 & 1.28 \\
\hline
\end{tabular}


Statistical results of statements relating to instrumental orientation towards Putonghua are shown in Table 9. The mean value greater than 3 for some statements indicates that local students tend to have positive attitudes towards Putonghua in view of its instrumental value though negative inclination to the social status of Putonghua in Hong Kong (see Statement 4) and students show an almost marginal attitude towards Putonghua learning motivation (see Statement 2). They barely agree that they look for opportunities to practice Putonghua (see Statement 12). However, students tend to agree strongly that Putonghua can help them get jobs since close connections between Mainland China and Hong Kong nowadays may probably promote more jobs opportunities concerning Putonghua. The results seem to indicate Putonghua has its limited pragmatic function in Hong Kong.

Generally speaking, Mainland students have a positive inclination to the instrumental value of Putonghua in Hong Kong except the social status of Putonghua in Hong Kong (see Statement 4). It is not surprising to find the students' learning motivation for higher proficiency of Putonghua in Hong Kong (see Statement 2) is not positive. The possible explanation for this partly is the entire Mainland students in this survey are all Putonghua speakers and partly is Putonghua is still developing its roles in Hong Kong. Mainland students seem to show a positive attitude towards Putonghua' future development, they tend to believe Putonghua is going to be important in the following years in Hong Kong (see Statement 6). In addition, they also tend to agree Putonghua will be used as a lingua franca for Mainlanders, Taiwanese, and Hong Kong people in the future (see Statement 18) which attaches a new function to Putonghua.

In general, results between the two groups of students' responses were quite similar in that they both agree the instrumental function of Putonghua and they also tend to disagree that currently Putonghua is highly regarded in Hong Kong. The results indicate that Mainland students seem to show a stronger confidence in the future of Putonghua than that of the local students (part of Research Question 3).

\subsection{Interactional Language between Mainland Students and Local Students}

In this survey, two questions were also designed in order to find out how Cantonese, English and Putonghua are used between the two groups of students' interaction. Results are displayed in the Table 10. From the table, it can be observed that the means value are clearly greater than 3 under each language choice given by Mainland students. This indicates that Mainland students like to use English, Cantonese and Putonghua to communicate with local students. Among these three language choices, English tends to be favored most by Mainland students. This may probably explain the strong instrumental orientation towards English shown by the Mainland students in the above results.

From the local students' aspect, the means value are greater than 3 for English and Putonghua but lower than 3 for Cantonese. This reveals local students on the other hand tend to show their preference of English and Putonghua when interact with Mainland students. Apart from this, the comparatively larger SD values under each language choice also reveal the responses among students are not unanimous.

Table 10. Interactional language between Mainland students and local students

\begin{tabular}{|c|c|c|c|c|c|c|}
\hline \multirow[t]{2}{*}{ Statement } & \multicolumn{2}{|c|}{ English } & \multicolumn{2}{|c|}{ Cantonese } & \multicolumn{2}{|c|}{ Putonghua } \\
\hline & Mean & SD & Mean & SD & Mean & SD \\
\hline $\begin{array}{l}\text { 9. For mainland student, when I interact with local students, I } \\
\text { like to speak the following language. }\end{array}$ & 3.43 & 1.61 & 3.17 & 1.57 & 3.03 & 1.47 \\
\hline $\begin{array}{l}\text { 10. For local student, when I interact with mainland students, I } \\
\text { like to speak the following language. }\end{array}$ & 3.27 & 1.39 & 2.87 & 1.63 & 3.13 & 1.38 \\
\hline
\end{tabular}

\subsection{Identity Perception of Hong Kong People between Local Students and Mainland Students}

Research has pointed close connection between language attitudes and identity (Such as Fishman, 2001; Giles \& Johnson, 1987 etc.) and a lot of studies in Hong Kong take account of the investigation of identity in their studies (such as Lai, 2005, 2012 etc.). As concerning the current study, it is a good clue for us to find out how local students identify themselves and how they are identified by the Mainland students based on the results discussed above.

A multiple-choice question is designed in the first part of the questionnaire aim to investigate how the identities of the two groups of students are constructed. They are asked to choose one answer from Hong Konger, Hong Kong Chinese, Chinese, No opinion and Others (if they choose it they need to specify). Percentage is calculated for this part. Statistical results are found in the Table 11. As the table shown, most local students $(\mathrm{N}=19)$ identified themselves as local identity Hong Kongers, 4 students identified themselves as Hong Kong Chinese; 
only 4 claimed themselves as Chinese, and 3 students cannot identify themselves.

Lau (1997) expected the double identity (Hong Kong Chinese) will become stronger after Hong Kong became part of China after 1997. However, from the current survey the tendency is not noticeable. The current results reveal local students emphasize their Hong Kong identity (63\%) a lot, with $17 \%$ of the students call themselves a double identity. This may explain the strong integrative orientation towards Cantonese shown by the local students in the above results. Another possible explanation of this is that local students regard Hong Kong as a developed place and its high international status in contrast to Mainland China, which they think as a developing place. Clearly, the current survey only involves 30 local respondents thus it is unrealistic to conclude the expectation of Lau is not exist. After all, 30 respondents are not enough to lead a definite conclusion.

Mainland students, on the other hand, showed different results with the local students. $47 \%$ of the students $(\mathrm{N}=14)$ gave a local identity to the local people, while $33 \%$ of the students $(\mathrm{N}=10)$ gave a double identity to the local people. $13 \%$ of the students $(\mathrm{N}=4)$ students gave a definite Chinese identity to them. And 2 students cannot identify the Hong Kong people.

From the results we can notice that Mainland students' concerning about some cultural barrier exists between the two groups of students as nearly half of the Mainland students (47\%) gave Hong Kong People a local identity. Referring the results about their interaction languages, we can observe that Mainland students favor English most when interact with local students rather than Putonghua. As Rampton (1999) noted people in a multilingual society use different languages or dialects for different identification purposes. Of course, this may be probably because of the efficiency for communication since English is the common language in university and at the same time local students' Putonghua proficiency is still developing as well as Mainland students' English proficiency is also developing.

At the same time, nearly half (46\%) of the Mainland students give Hong Kong people a double identity and a complete Chinese identity, this on the other hand showing deep connections between the two groups. After all, both groups of student share the same heritage.

Table 11. Identity perception of Hong Kong people between local students and Mainland students

\begin{tabular}{|c|c|c|c|c|c|}
\hline \multirow[t]{2}{*}{ Questions } & \multirow[t]{2}{*}{ Options } & \multicolumn{2}{|c|}{ Local students } & \multicolumn{2}{|c|}{ Mainland China students } \\
\hline & & $\%$ & $\begin{array}{l}\text { No. of } \\
\text { students }\end{array}$ & $\%$ & $\begin{array}{l}\text { No. of } \\
\text { students }\end{array}$ \\
\hline \multirow{6}{*}{$\begin{array}{l}\text { 5. How would you describe your identity } \\
\text { (for local students)?/ } 6 \text {. How would you } \\
\text { describe the Hong Kong people's identity } \\
\text { (for Mainland students)? }\end{array}$} & Hong Konger & 63 & 19 & 47 & 14 \\
\hline & Hong Kong Chinese & 17 & 5 & 33 & 10 \\
\hline & Chinese & 10 & 3 & 13 & 4 \\
\hline & No opinion & 10 & 3 & 6 & 2 \\
\hline & Others & 0 & 0 & 0 & 0 \\
\hline & TOTAL & & 30 & & 30 \\
\hline
\end{tabular}

\section{Conclusion}

\subsection{English Still as a Linguistic Capital in Hong Kong}

Since the handover, serious efforts have been made by the Hong Kong government to move the "Biliteracy and Trilingualism" to Mother Tongue Policy. English still survived as the most prestigious language and retains its high social status. English has undergone an interesting process from an alien foreign language to an important medium of communication in the current community (Lai, 2005). Both groups of students seem to highly regard English for its instrumental value as the results revealed. All of these indicated English successfully kept its high status in Hong Kong. As Chew (2007) pointed that English was the language that attracted foreign investment and gave the society its leading role in education, academic achievement, international trade and business. The use of this dominant language is seen as a form of linguistic capital (Bourdieu, 1991) and can be shifted into other forms of capital like education and incomes (Chew, 2007). In the 21 century, English has its unique function in Hong Kong and has already become the key to open success and create future.

\subsection{The Highly Pragmatic Function of Putonghua}

Putonghua has become a third-important language after the return of Hong Kong to China and is expected to follow into the footsteps of English which will generate another language shift in Hong Kong. Several policies made Putonghua successfully landed in Hong Kong, such as "Biliteracy and Trilingualism". Immediately followed by this is the change of school curriculum that Putonghua has become a new core subject from Primary 
1 to Secondary. Besides this, the close contacts maintained between Mainland China and Hong Kong also accelerates the development of Putonghua. As Pennington (1998) predicts the next language shift in Hong Kong is the Putonghua being the center of change. The results showed students' attitude toward Putonghua was much enhanced during those years (2012).

As the findings from the current study suggest, local university students show a near positive attitude towards Putonghua and they tend to favor Putonghua much more for its instrumental value rather than its integrative value. It seems Putonghua has developed well its pragmatic function in Hong Kong. For the Mainland students who participated in this study, they tend to show more favor to Putonghua when compared with the local students. They also realize the instrumental value of Putonghua in Hong Kong. However, Mainland students seem to show weak positive attitudes towards Putonghua in the perspective of the integrative orientation in the context of Hong Kong. They hold strong integrative orientation towards Putonghua without the context of Hong Kong. The reason for this is probably the negative news related to some mainlanders and Putonghua is still not regarded as a prestigious language in Hong Kong. In addition, the status of English is still stronger than Putonghua in some domains in Hong Kong.

The status of Putonghua is still developing and will be stronger with the arising of international status of PRC as well as its economic prosperity. In addition, it is the lingual franca used among Mainland China, Hong Kong and Taiwan. Therefore, the subtle transition is happening with time.

\subsection{Cantonese Remains as a Strong Dialect}

As Fishman (1967) pointed out that a "diglossic situation" in Hong Kong in which English functions socially and Cantonese is used for daily purpose. Cantonese has rooted in most daily communications in Hong Kong, thus it is not surprising to find local students show their positive attitudes towards it. In addition, all of these respondents began their education under the Mother Tongue Policy though the government relaxes the policy in 2009 and gives the choice back to the school. In fact, Hong Kong remains the only place in China where Cantonese, the local dialect of the majority of its residents, is the official medium of instruction for primary schools (Tse et al., 2007) and only a few secondary schools can have the qualification to use English as the medium of instruction. Having been educated by the Cantonese medium of instruction, the students in this generation would use more Cantonese at school and home.

Facing this totally new dialect, Mainland students also show their positive attitudes towards it even though their responses are not as strong as the local students. After all Cantonese is still the most commonly used language in and out the classroom though English is the medium of instruction of universities in Hong Kong.

\subsection{Different Languages for Different Identification Purposes}

Triglossic situation is gradually formed in the Universities of Hong Kong by both Mainland students and local students. English, Cantonese, and Putonghua consistently shifted between these two groups of students. Under such situation in universities students have a variety of different languages for different purposes. Rampton (1999) noted people under a multilingual society where they have different languages or dialects for different identification purposes, and exercise symbolic power in various ways in order to be heard and respected. Like the local students in this study they stick to their Hong Kong identity but they tend to show positive attitudes to Putonghua when interacting with local students. In fact, Hong Kong students' preference for Putonghua for interaction with Mainland students is not intended to establish close relation but to differentiate these communications from those within the Hong Kong group (Gu, 2011).

On the other hand, Mainland students tend to show more inclination to use English when interacting with local students. Concerning communication efficiency, all the Mainland respondent are non-native Cantonese speakers since English is the instruction language in universities thus it is not surprising to find Mainland students use English more to communicate with local students. Generally speaking Mainland students show positive inclination towards Putonghua, Cantonese and English which also indicate that during interactions with Hong Kong students, mainland students try to symbolize their multicultural exposure (Gu, 2011).

With the change of the sovereignty, Hong Kong has performed well under the process of localization and mainlandization as well as maintained its international position. Cantonese-the local dialect, Putonghua-the official language of China and English-the international language as well as the former British colonial language, an intense interplay among these languages made the language attitudes different among the students. In addition the large numbers of Mainland students studying in Hong Kong who share the same community with the local students. Therefore, a full picture of Hong Kong language attitude can be drawn from both local students and Mainland students. 
In the 21centutry, English, Cantonese and Putonghua practice in different domains of Hong Kong with their unique function. As the results showed, both groups of students showed positive inclination to these three languages in terms of the instrumental orientation. Regarding the integrative orientation towards these languages, Cantonese and English are still in high position compared with Putonghua. Since the end of British's sovereignty, Hong Kong is making itself to localization as well as mainlandization. The result of this is the rising status Cantonese and Putonghua are. Although Putonghua ranks not as high as Cantonese, however, the change is happening with the context. After all, the language attitude is slow process we cannot expect something happen overnight.

\section{References}

Axler, M., Yang, A., \& Stevens, T. (1998). Current language attitudes of Hong Kong Chinee adolescents and young adults. In M. C. Pennington (Ed.), Language in Hong Kong at Century's End (pp. 391-418). Hong Kong: Hong Kong University Press.

Baker, C. (1992). Attitudes and language. Clevedon/Philiadelphia/Adelaide: Multilingual Matters.

Bourdieu, P. (1991). Language and symbolic power. Cambridge: Polity Press.

Chew, P. G. L. (2007). Remarking Singapore: Language, culture, and identity in a globalized world. In A. Tsui \& J. Tollefson (Eds.), Language policy, culture, and identity in Asian contexts (pp. 73-93). Mahwah, NJ: Lawrence Erlbaum.

Fasold, R. (1984). The sociolinguistics of society. Oxford: Blackwell.

Fishman, J. (1967). Bilingualism with and without diglossia. Journal of Social Issues, 23(2), 29-38. https://doi.org/10.1111/j.1540-4560.1967.tb00573.x

Fishman, J. (2001). Handbook of language and ethnicity. New York: Oxford University Press.

Gardner, R. C., \& Lambert, W. E. (1972). Attitudes and motivation in second language learning. Rowley, MA: Newbury House.

Gardner, R. C. (1985). Social psychology and second language learning: The role of attitudes and motivation. London \& Baltimore: Edward Arnold.

Gardner, R., (2001). Integrative motivation and second language acquisition. In Z. Dornyei \& R. W. Schmidt (Eds.), Motivation and Second Language Acquisition (pp. 1-20). University of Hawaii, Honolulu.

Giles, H., \& Johnson, P. (1987). Ethnolinguistic identity theory: A social psychological approach to language maintenance. International Journal of the Sociology of Language, 68, 69-99. https://doi.org/10.1515/ijsl.1987.68.69

$\mathrm{Gu}, \mathrm{M}$. (2011). Language choice and identity construction in peer interactions: An insight from a multilingual university in Hong Kong. Journal of Multilingual and Multicultural Development, 32(1), 17-31. https://doi.org/10.1080/01434632.2010.532876

Hyland, K. (1997). Language attitudes at the handover: Communication and identity in 1997 Hong Kong. English World-wide, 18(2), 191-210. https://doi.org/10.1075/eww.18.2.03hyl

Lai, M. L. (2001). Hong Kong Students' Attitudes towards Cantonese, Putonghua and English after the Change of Sovereignty. Journal of Multilingual and Multicultural Development, 22(2), 112-133. https://doi.org/10.1080/01434630108666428

Lai, M. L. (2005). Language attitudes of the first postcolonial generation in Hong Kong secondary schools. Language in Society, 34(4), 363-388. https://doi.org/10.1017/S004740450505013X

Lai, M. L. (2012). Tracking language attitudes in postcolonial Hong Kong: An interplay of localization, mainlandization, and internationalization. Journal of Multilingual and Multicultural Development, 31(1), 83-111. https://doi.org/10.1515/mult.2012.004

Lamb, M. (2004). Integrative motivation in a globalizing world. System, 32, 3-19. https://doi.org/10.1016/j.system.2003.04.002

Lau, S. K. (1997). Hongkongese or Chinese-The problem of identity on the eve of resumption of Chinese sovereignty over Hong Kong. Hong Kong Institute of Asia-Pacific Studies, Chinese University of Hong Kong.

Lord, R. (1987). Language policy and planning in Hong Kong: Past, present and (Especially) future. In R. Lord \& N. L. H. Cheng (Eds.), Language Education in Hong Kong (pp. 3-26). Hong Kong: Chinese University 
Press.

Pennington, M. C., \& Yue, F. (1994). English and Chinese in Hong Kong: pre-1997 language attitudes. World Englishes, 13(1), 1-20. https://doi.org/10.1111/j.1467-971X.1994.tb00279.x

Pennington, M. C. (1998). Colonialism's aftermath in Asia: A Snapshot View of Bilingualism in Hong Kong. Hong Kong Journal of Applied Linguistics, 3(1), 1-16.

Peter, G. (2010). Attitudes to language. Cambridge: Cambridge University Press.

Pierson, H. (1994) Cantonese, English, or Putonghua - unresolved communicative issue in Hong Kong's Future. In G. A. Postiglione (Ed.), Education and Society in Hong Kong-Toward One Country and Two Systems (pp. 168-183). Hong Kong: Chinese University Press.

Pierson, H. D., Fu, G. S., \& Lee, S. Y. (1980). An analysis of the relationship between language attitudes and English attainment of secondary school students in Hong Kong. Language Learning, 30, 289-316. https://doi.org/10.1111/j.1467-1770.1980.tb00320.x

Rampton, B. (1999). Dichotomies, difference and ritual in second language teaching and learning. Applied Linguistics, 20(3), 316-340. https://doi.org/10.1093/applin/20.3.316

Thurstone, L. (1931). The measurement of social attitudes. Journal of Abnormal and Social Psychology, 26, 249-269. https://doi.org/10.1037/h0070363

Tung, C. H. (1997). Building Hong Kong for a new era. Address by the Chief Executive the Honourable Tung Chee Hwa at the Provisional Legislative Council meeting on 8 October 1997.The Hong Kong Special Administrative Region of the People's Republic of China.

Tse, S. K., Lam, J. W. I., Loh, E. K. Y., \& Lam, R. Y. (2007). The influence of the language that Hong Kong primary school students habitually speak at home on their Chinese reading ability in school. Journal of Multilingual and Multicultural Development, 28(5), 400-417. https://doi.org/10.2167/jmmd529.1

Yau, S. C. (1992). Language policies in post-1997 Hong Kong. In K. K. Luke (Ed.), Into the Twenty-first Century-Issues of Language in Education in Hong Kong (pp. 15-29). Hong Kong: Linguistic Society of Hong Kong.

Note.

EAP Class of City University of Hong Kong: A pre-course to Gateway Education (GE) English courses to all the students in the university. Students under this course are normally Grade E in HKAL Use of English or Grade 3 in HKDSE.

\section{Appendix}

Thank you for answering this questionnaire. The questionnaire is designed to investigate the language attitudes in Hong Kong. Your responses are only used for analysis purposes. Thank you for your cooperation!

\section{Part I: Personal Language Information}

1. Major:

2. Are you a local student or Mainland China Student? (Please circle the answer)
A. Local student
B. Mainland China Student

\section{For local student, please answer the following questions. Thank you!}

3. What language(s) /dialect(s) can you speak?

4. What language (s) do you use most often in your daily life?

5. How would you describe your identity?
A. a Hongkonger
B. a Chinese
C. a Hong Kong Chinese
D. no opinion
E. others (please specify:

$$
\text { ) }
$$


For Mainland China student, please answer the following questions. Thank you!

3. Birth of place:

4. What language(s) /dialect(s) can you speak?

5. What language (s) do you use most often in your daily life in HK?

6. How long have you been in Hong Kong?
A. Less than 2 years
B. 2 years
C. more than 2 years

7. How would you describe the Hong Kong people's identity?
A. a Hongkonger
B. a Chinese
C. a Hong Kong Chinese
D.no opinion
E. others (please specify:

\section{Part II: Language Attitudes}

Instructions: Put a tick $(\sqrt{ })$ in the box which represents your opinion for the following statements.

$1=$ strongly disagree, $2=$ disagree, $3=I$ have no idea, $4=$ Agree, $5=$ strongly agre

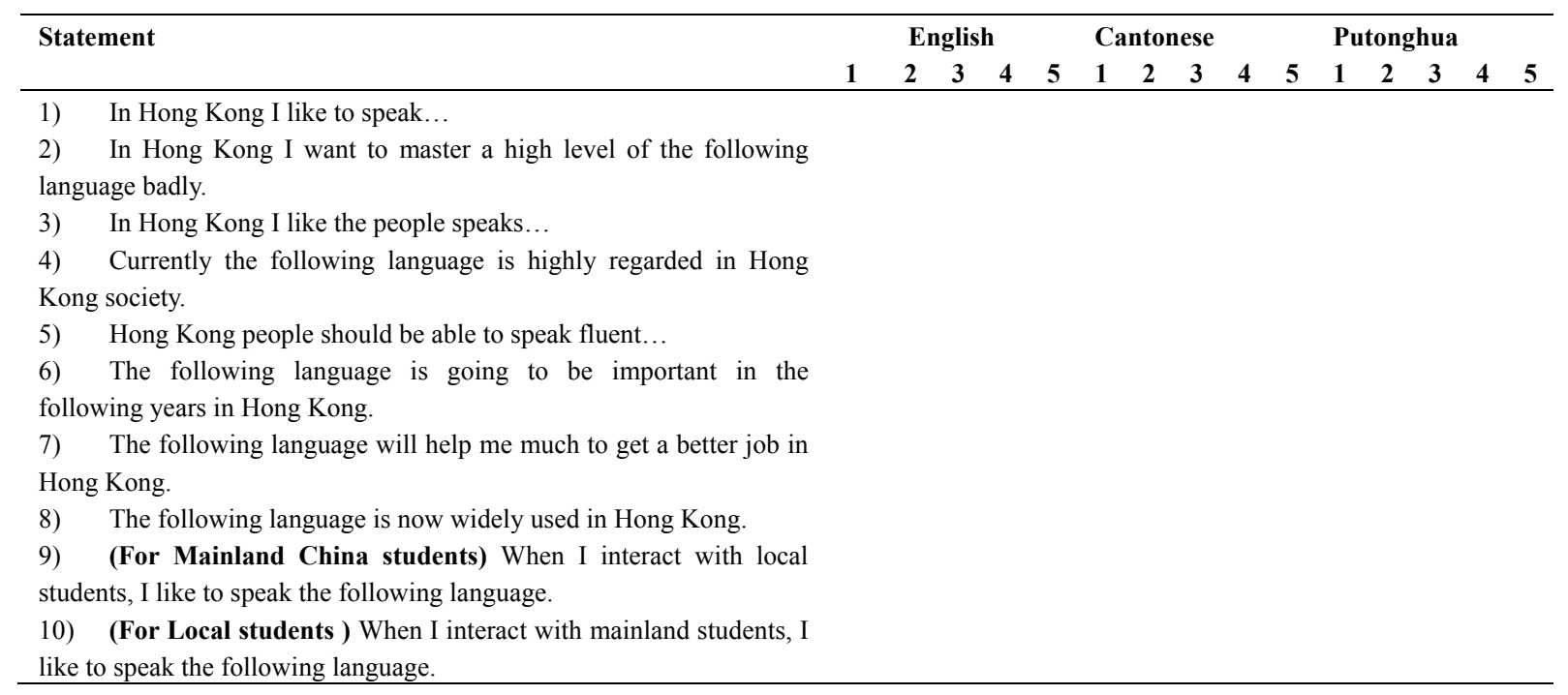

\section{Put a tick $(\sqrt{ })$ in the box which represents your opinion for the following statements.}

$1=$ strongly disagree, $2=$ disagree, $3=I$ have no idea, $4=$ Agree, $5=$ strongly agree

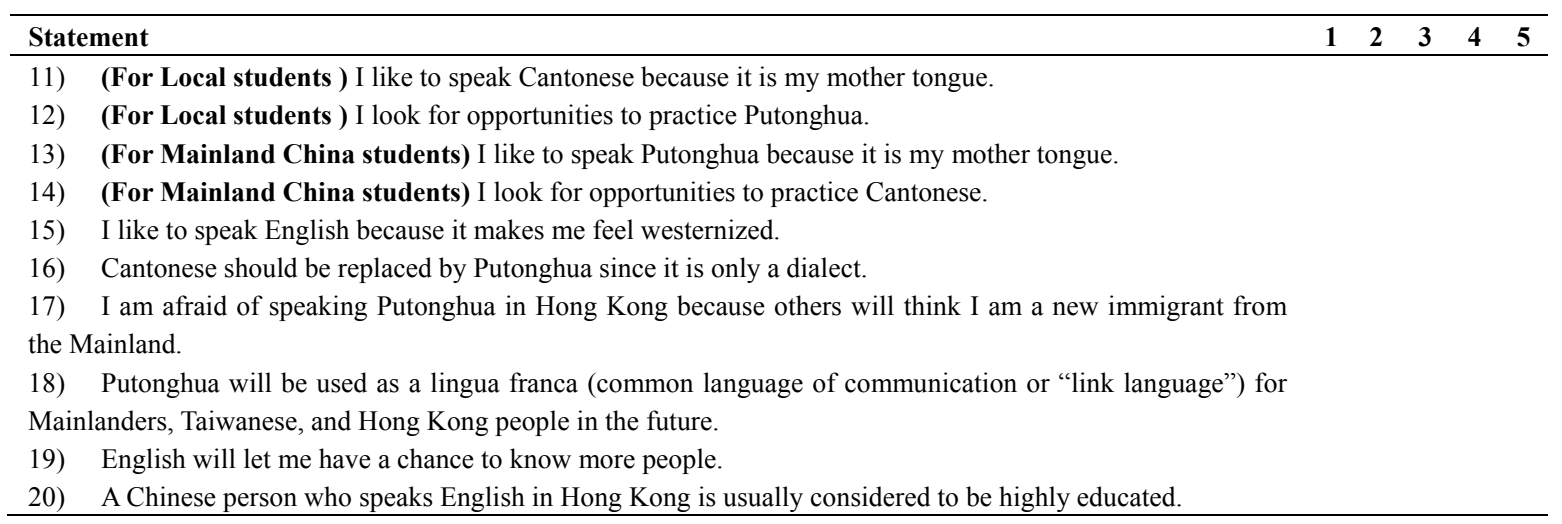

Thank you so much! 


\section{Copyrights}

Copyright for this article is retained by the author(s), with first publication rights granted to the journal.

This is an open-access article distributed under the terms and conditions of the Creative Commons Attribution license (http://creativecommons.org/licenses/by/4.0/). 